\title{
Current Control Method of WRSM in High-speed Operation Range
}

\author{
Jae-Jun Lee*, Ki-Doek Lee*, Ik-Sang Jang**, Sung-Gu Lee ${ }^{* * *}$, Woong-Chan Chae ${ }^{\S}$, \\ Hyung-Woo Lee ${ }^{\S \S}$ and Ju Lee ${ }^{\dagger}$
}

\begin{abstract}
This Paper analyzes the characteristics of the WRSM in high-speed operation range. To verify the control characteristics of various WRSM models, the relative position of the central point of current limit circle and voltage limit ellipse is defined as $M$ value and 3 models according to $M_{\max }$ value are designed through inductance change. Through the designed models, the current control method of 3-variables control for maximum power especially in high-speed operation range is presented.
\end{abstract}

Keywords: Current limit circle, High-speed operation, Voltage limit ellipse, WRSM

\section{Introduction}

Due to the depleting pool of natural resources and pollution issues which came hand in hand with the recent dramatic increase of fossil fuels use, studies on eco-friendly vehicles such as Hybrid Electric Vehicle (HEV) and Electric Vehicle (EV) which are to be used as alternative means of transportation are conducted at national and corporate level.

Permanent Magnet Synchronous Motor (PMSM) is mainly used as the traction motor of HEV and EV, because it has the high torque density and the wide operating range. However, due to the price increase and uncertainty of supply of rare earth materials used in the PMSM, the development of non-rare earth electric motors have been highly demanded [1].

Recently, Wound Rotor Synchronous Motor (WRSM), one of the non-rare earth motors, has been researched for traction motor of HEV and Integrated Starter Generator (ISG) motor.

The commonly known advantages of WRSM are that temperature coefficient correction due to high temperature of permanent magnet and demagnetization phenomenon do not need to be considered and power factor control is possible. In aspect of control, WRSM which has 3 control variables $\left(i_{d}, i_{q}, i_{f}\right)$, has the advantage that there are various control methods due to increase of degree of freedom [2]. But it means that finding appropriate current combinations is difficult work.

$\dagger$ Corresponding Author: Dept. of Electrical Engineering, Hanyang University, Korea. (julee@hanyang.ac.kr)

* Dept. of Electrical Engineering, Hanyang University, Korea. (genius_call@hotmail.com)

** Mechatronics Group, Defence Program R\&D Center, Samsung Techwin Co., Korea. (coldest81@gmail.com)

*** R\&D Team, Digital Appliances, Samsung Electronics Co., Korea. (suggu.lee@samsung.com)

$\S \quad$ Research \& Development Division, Hyundai Motor Co, Korea. (chaewc@hyundai.com)

$\S \S$ Dept. of Railway Vehicle System Engineering, Korea National University of Transportation, Korea. (krhwlee@ut.ac.kr)

Received: January 28, 2015; Accepted: May 13, 2015
For this complexity, we propose the maximum power control method for 3 variables at especially high-speed operation range from the perspective of $\mathrm{M}$ value defined as the ratio of current limit circle and the central point of voltage limit ellipse.

\section{Basic Theory of Control}

To analyze the characteristics, basic model design of $150 \mathrm{~kW}$-class WRSM for traction in an HEV is conducted. Fig. 1 is Basic model of WRSM and Table 1 shows

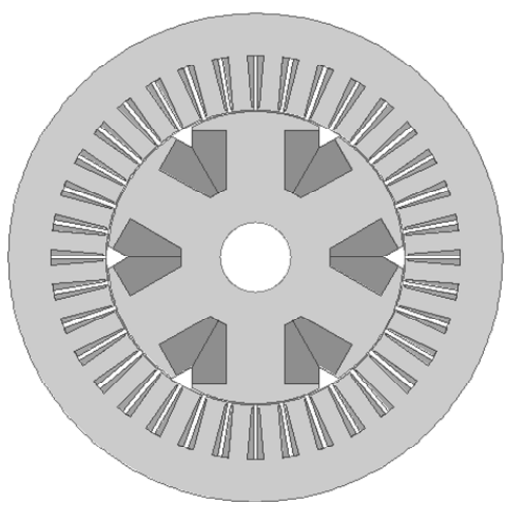

Fig. 1. Basic model of WRSM

Table 1. Specifications of basic model

\begin{tabular}{c|c|c}
\hline & Value & Unit \\
\hline Poles / Slots & $6 / 36$ & - \\
\hline Stator Diameter & 350 & $\mathrm{~mm}$ \\
\hline Stack Length & 140 & $\mathrm{~mm}$ \\
\hline Battery Voltage & 620 & $\mathrm{~V}$ \\
\hline Stator Current Density & 10.6 & $\mathrm{~A}_{\mathrm{rms}} / \mathrm{mm}^{2}$ \\
\hline Stator Phase Current & 275 & $\mathrm{~A}_{\mathrm{rms}}$ \\
\hline Turns per Phase & 24 & - \\
\hline Rotor Current Density & 5.5 & $\mathrm{~A}_{\mathrm{DC}} / \mathrm{mm}^{2}$ \\
\hline Rotor Current & 20 & $\mathrm{~A}_{\mathrm{DC}}$ \\
\hline Turns per Pole & 110 & - \\
\hline
\end{tabular}


specifications of the WRSM.

To check power characteristics at high speed area of WRSM, driving area satisfying the current constraints and voltage constraints needs to be checked. First, field current and phase current can be applied under the maximum field current $i_{f m}$ and phase current $I_{a m}$ which are determined by heat saturation or controller data, etc, as shown in (1), (2).

In d-q reference frame [3], current phase angle is defined as angle between $q$-axis and stator current vector, and as positive value when stator current vector is located to the second quadrant.

Voltage constraint also needs to be checked for high speed operation as shown in (3).

$$
\begin{gathered}
i_{f} \leq i_{f m} \\
i_{d}^{2}+i_{q}^{2} \leq I_{a m}^{2} \\
\frac{\left(i_{d}+\frac{L_{m} i_{f}}{L_{d}}\right)^{2}}{\left(\frac{V_{o m}}{\omega_{e} L_{d}}\right)^{2}}+\frac{\left(i_{q}\right)^{2}}{\left(\frac{V_{o m}}{\omega_{e} L_{q}}\right)^{2}}=1
\end{gathered}
$$

where $L_{d}$ is the $d$-axis inductance, $L_{q}$ is the $q$-axis inductance, $L_{m}$ is the mutual inductance between rotor and stator, $V_{o m}$ is the constraint of voltage.

In (3), it can be seen that the voltage limit ellipse is related with the field current. This feature of WRSM is distinguished from that of PMSM. By reducing field current, called Field-weakening control, the central point of voltage limit ellipse can be moved to the starting point side as shown in Fig. 2.

In (3), the $d$-axis and $q$-axis inductances which are used in the flux-weakening control of PM brushless ac machines can be calculated from [4]. However, inductances have to be calculated by considering saturation $[5,6]$. Under the saturation condition, inductances of WRSM can be calculated using FE analysis as follows.

$$
\begin{gathered}
L_{m}=\frac{\psi_{o} \cos \alpha}{i_{f}} \frac{F_{f}}{F_{f}+F_{d}} \\
L_{d}=\frac{\psi_{o} \cos \alpha}{i_{d}} \frac{F_{d}}{F_{f}+F_{d}} \\
L_{q}=\frac{\psi_{o} \sin \alpha}{i_{q}}
\end{gathered}
$$

Where $\psi_{o}$ is the total magnetic flux interlinkage, $\alpha$ is the load angle, $F_{f}$ is the MMF source representing the rotor, $F_{d}$ is the MMF source representing the $d$-axis current of stator.

As shown in Fig. 2, the size of voltage limit ellipse reduces as the field current becomes smaller due to the increase of d-axis, q-axis inductance.

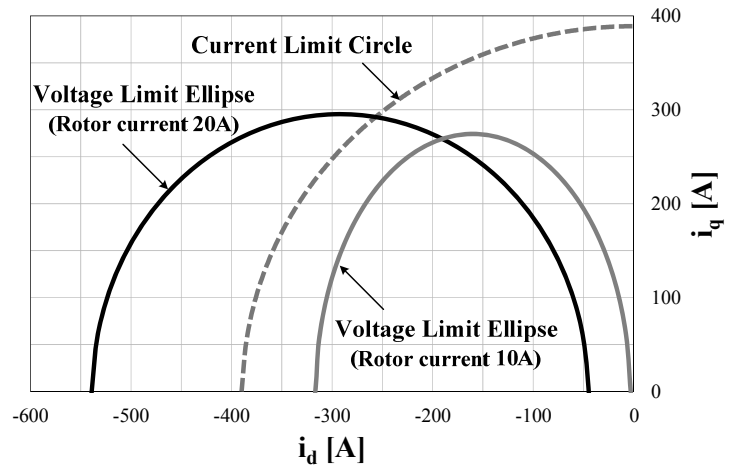

Fig. 2. Voltage limit Ellipse @ 5000rpm

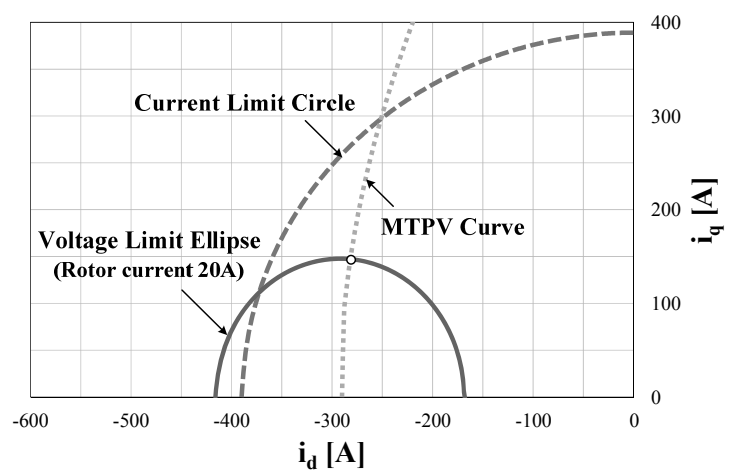

Fig. 3. Voltage limit Ellipse \& MTPV curve @ 10000rpm

Fig. 3 shows current limit circle and voltage limit ellipse, MTPV curve at 10000rpm for WRSM when field current is maximum value $\left(i_{f}=i_{f m}\right)$. MTPV curve is the condition of generating maximum torque for the same magnetic flux linkage [7]. MTPV curve related to the central point of voltage limit ellipse is formed inside of current limit circle as shown in Fig. 3. Therefore, the point of intersection with MTPV curve becomes the maximum power control condition of basic model when driving at 10000rpm.

\section{Design According to $M_{\max }$}

The ratio for parameters $\left(-L_{m} i_{f} / L_{d}\right), I_{a}$ determining current limit circle and the central point of voltage limit ellipse is defined as $\mathrm{M}$.

$$
M=\frac{L_{m} i_{f}}{L_{d} I_{a}}
$$

To determine the control characteristics at high speed of motor, fixed $\mathrm{M}$ value when applying maximum field current and maximum phase current is defined as (8).

$$
M_{\max }=\frac{L_{m} i_{f m}}{L_{d} I_{a m}}
$$

Basic model is the model that the central point of 
voltage limit ellipse is located inside than current limit circle $\left(\mathrm{M}_{\max }<1\right)$.

As shown in (9), (10), $L_{m}$ is proportional to the multiplication of turns of rotor and stator, and $L_{d}$ is proportional to the square of turns of stator [8].

$$
\begin{gathered}
L_{m}=\frac{N_{a} N_{f}}{R_{d}} \\
L_{d}=\frac{N_{a}^{2}}{R_{d}}
\end{gathered}
$$

where $R_{d}$ is the reluctance of d-axis, $N_{f}$ is the turns of rotor, $N_{a}$ is the turns of stator.

Design of changing $\mathrm{M}_{\max }$ is conducted by changing turns of rotor and stator under the same stator diameter, stack length, current constraints.

Case $2\left(\mathrm{M}_{\max }=1\right)$ is that the central point of voltage limit ellipse matches with current limit circle and case 3 $\left(\mathrm{M}_{\max }>1\right)$ is that the central point of voltage limit ellipse is located outside of current limit circle. Specifications of WRSM redesigned by size of $\mathrm{M}_{\max }$ value are shown in Table 2 .

In the low speed operation region, MTPA control is required [9]. The values of comparing FEA results of torque, efficiency at rated speed are shown in Table 3.

Table 2. Specifications of WRSM

\begin{tabular}{c|c|c|c|c}
\hline & Case1 & Case2 & Case3 & Unit \\
\hline $\mathrm{M}_{\max }$ & 0.75 & 1 & 1.32 & - \\
\hline Stator Diameter & \multicolumn{3}{|c}{350} & $\mathrm{~mm}$ \\
\hline Stack Length & \multicolumn{3}{|c}{140} & $\mathrm{~mm}$ \\
\hline Rotor Diameter & 210 & 219 & 230 & $\mathrm{~mm}$ \\
\hline Turns per phase & 24 & 22 & 20 & - \\
\hline Turns per pole & 110 & 114 & 120 & - \\
\hline
\end{tabular}

Table 3. Maximum torque of WRSM @ rated speed

\begin{tabular}{c|c|c|c|c}
\hline & Case1 & Case2 & Case3 & Unit \\
\hline Torque & 394.1 & 396.7 & 393.8 & $\mathrm{Nm}$ \\
\hline Current Phase Angle & 5 & 7 & 8 & $\mathrm{degE}$ \\
\hline Efficiency & 96.5 & 96.7 & 96.9 & $\%$ \\
\hline
\end{tabular}

\section{Control Method for Maximum Power in High-speed Operation Range}

\subsection{Model of case1 $\left(M_{\max }<1\right)$}

Fig. 4 shows the torque (contour line) \& voltage limit area (white dotted line area) according to the current phase angle and the field current of case 1. It can be seen in Fig. 4 that maximum field current must be maintained without reducing field current to generate larger torque in the area satisfying voltage limits.

And while fixing field current to the maximum value, the torque graph according to the change in phase current

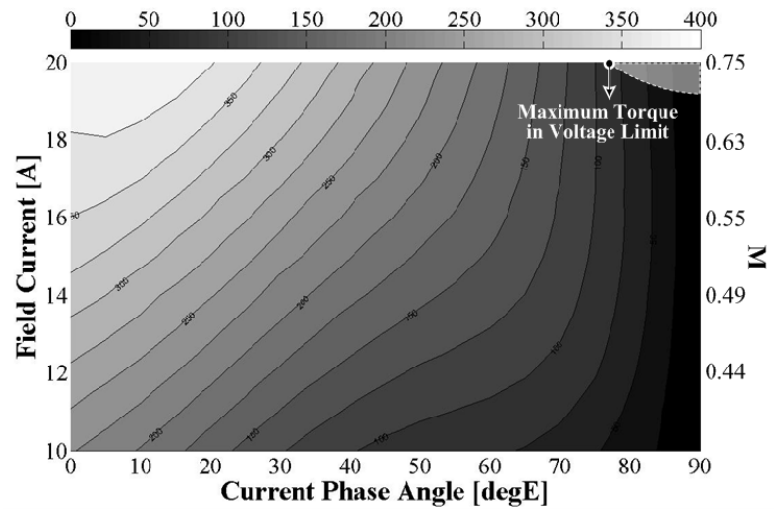

Fig. 4. Torque, voltage limit area, $M$ value of case 1 according to the field current and the current phase angle

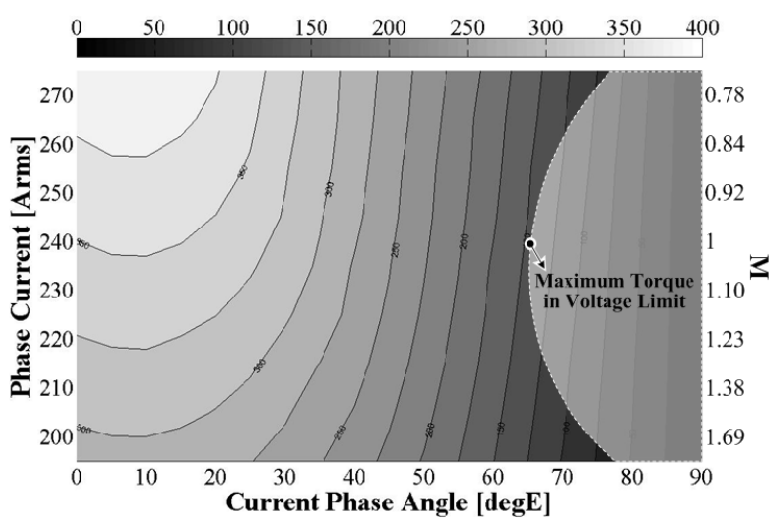

Fig. 5. Torque, voltage limit area, $M$ value of case 1 according to the phase current and the current phase angle

size is shown in Fig. 5. It can be seen in Fig. 5 that maximum torque is generated when driving 10000rpm at phase current $240 \mathrm{~A}_{\mathrm{rms}}$ not maximum phase current. This area meets MTPV control condition. As phase current $I_{a}$ is reduced, $M$ value increases gradually and the analytical results showed that $\mathrm{M}$ value at phase current $240 \mathrm{~A}_{\mathrm{rms}}$ was close to 1 .

Therefore, in the case 1, control for maximum power is to maintain field current as the maximum value and control current phase angle and then MTPV control.

\subsection{Model of case2 $\left(M_{\max }=1\right)$}

In case2, the torque and operable area at maximum speed are shown in Fig. 6. It is seen that the control method for maximum power is to maintain field current and phase current as the maximum value and adjust current phase angle in the case 2 .

\subsection{Model of case3 $\left(M_{\max }>1\right)$}

In Fig. 7, it is seen that the maximum torque generation point for case 3 in the voltage limit area satisfying 


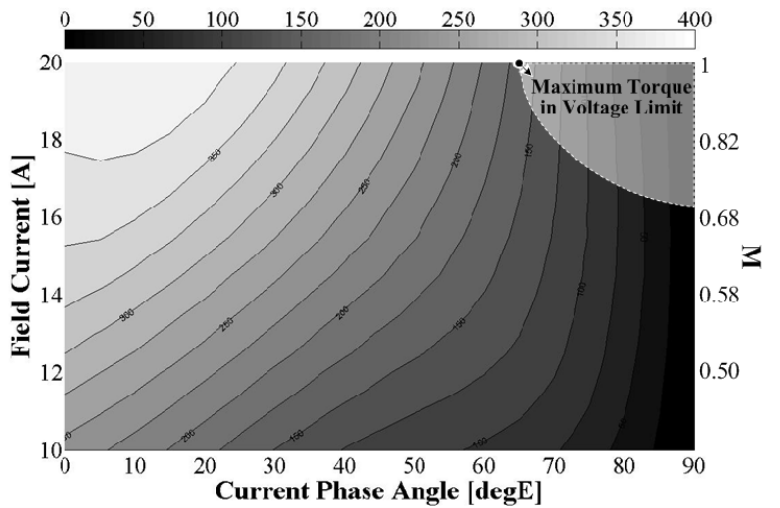

Fig. 6. Torque, voltage limit area, $M$ value of case 2 according to the field current and the current phase angle

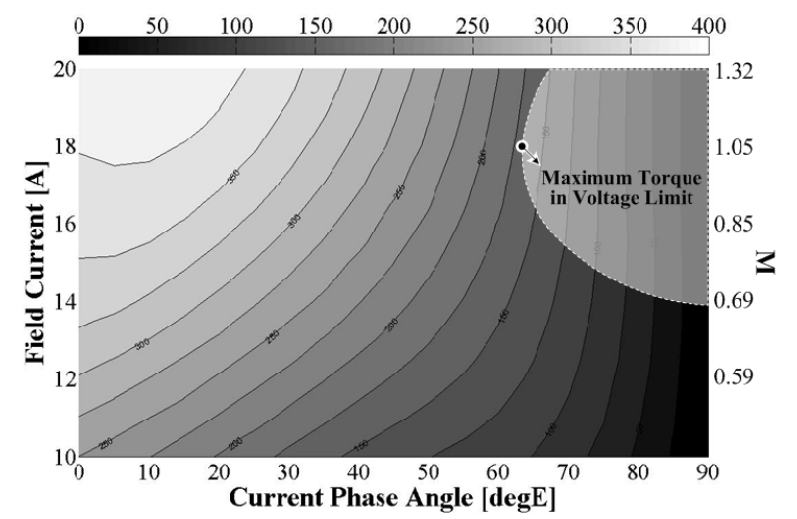

Fig. 7. Torque, voltage limit area, $M$ value of case 3 according to the field current and the current phase angle.

$10000 \mathrm{rpm}$ driving is not when maximum field current is applied. When applying field current $17.5 \mathrm{~A}$ rather than maximum field current $20 \mathrm{~A}$, maximum torque is generated in the area satisfying the voltage limit.

As $M$ value decreases gradually, it can be seen that the case of field current $17.5 \mathrm{~A}$ is the point of $\mathrm{M}=1$.

Accordingly, in the case $3\left(\mathrm{M}_{\max }>1\right)$, the control condition for maximum power is to reduce field current during high speed control. At that time field current is reduced up to the area where $M$ value satisfies 1 .

\section{Conclusion}

This paper analyzed power characteristics of $150 \mathrm{~kW}$ class WRSM for traction and presented the direction on the current control method at high-speed range. High-speed operation control of WRSM is more complicated than that of PMSM due to the field current control.

Due to the complexity of 3-variables current control, M value was defined by the relative position of the central point of voltage limit ellipse and current limit circle. The current control method at high speed varies depending on unique $\mathrm{M}_{\max }$ value of each model. The cases are classified into 3 depending on $\mathrm{M}_{\max }$ values and the current control method at high speed was presented for each case.

In those three cases, controlling phase current and field current to converge $M$ value to 1 at high speed can be seen to be the maximum power condition.

\section{Acknowledgements}

This work was supported by the National Research Foundation of Korea (NRF) grant funded by the Korea government (MSIP) (No.2013R1A2A1A01015171)

\section{References}

[1] G. Friedrich, "Experimental comparison between Wound Rotor and Permanent Magnet Synchronous machine for Integrated Starter Generator applications", Energy Conversion Congress and Exposition (ECCE 2010), pp.1731-1736, 2010.

[2] A. Girardin, G. Friedrich, "Optimal control for a Wound Rotor Synchronous starter generator”, Industry Applications Conference, pp.14-19, 2006.

[3] H. Ben Hamed, N. Bernard, G. Feld, B. Multon, Machines synchrones, Fonctionnement en régime autopiloté. Techniques de l'ingénieur. D 3524.

[4] Y. S. Chen, Z. Q. Zhu, "Calculation of d- and q-Axis Inductances of PM Brushless ad Machines Accounting for Skew", IEEE Transactions on Magnetics, Vol. 41, No. 10, pp. 3940-3942, October 2005.

[5] E.Levi, "State-space d-q axis models of saturated salient pole synchronous machines", IEE Proc.-Electr. Power Appl., Vol. 145, No. 3, pp. 206-216, May 1998.

[6] K.J. Meessen, P. Thelin, J. Soulard, E.A. Lomonova, "Inductance Calculations of Permanent-Magnet Synchronous Machines Including Flux Change and Self- and Cross-Saturations", IEEE Transactions on Magnetics, Vol. 44, No.10, pp. 2324-2331, October 2008.

[7] S. Morimoto, Y. Takeda, T. Hirasa, K. Taniguchi, "Expansion of Operating Limits for Permanent Magnet Motor by Current Vector Control Considering Inverter Capacity", IEEE Trans. On Industry Applications, IA-26, No. 5, pp. 866-871, 1990.

[8] Ju Lee, Electric machinery, Hongrung publishing company, 2011.

[9] S. Morimoto, K. Hatanaka, Y. Tong, Y. Takeda, T. Hirasa, "Servo Drive System and Control Characteristics of Salient Pole Permanent Magnet Synchronous Motor", IEEE Transactions on Industry Applications, Vol. 29, No. 2, pp.338-343, 1993. 


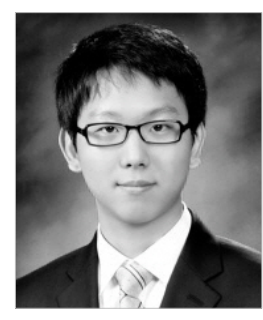

Jae-Jun Lee He received his B.S. and M.S. degrees in Electrical Engineering from Hanyang University, Seoul, Korea in 2009 and 2011, respectively. Since 2011, he has been pursuing the Ph.D. degree at the Department of Electrical Engineering, Hanyang University. His research interests include motor design, analysis of motor / generator; and applications of motor drive, such as electric vehicles, home appliances.

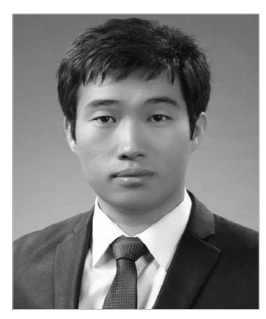

Ki-Doek Lee He received his M.S. and $\mathrm{Ph} . \mathrm{D}$ degrees in Electrical Engineering from Hanyang University, Seoul, Korea in 2011 and 2015 respectively. He is now working in Hanyang University. His research interests include motor design, analysis of motor / generator; and applications of motor drive, such as electric vehicles, home appliances.

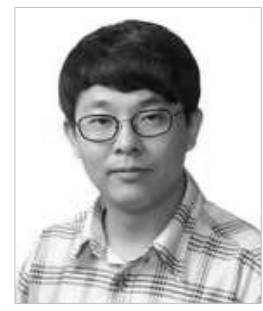

Ik-Sang Jang He received his B.S., M.S. and Ph.D. degrees in Electrical Engineering from Hanyang University, Seoul, Korea in 2007, 2009 and 2012 respectively. $\mathrm{He}$ is now working in Samsung Techwin Co. His research interests include motor design, analysis of motor / generator; and applications of motor drive, such as hybrid and electric vehicle.

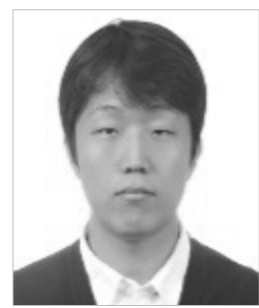

Sung-Gu Lee He received his B.S., M.S. and Ph.D. degrees in Electrical Engineering from Hanyang University, Seoul, Korea in 2003, 2005 and 2009, respectively. He is now working in Samsung Electronics Co. His research interests include motor design, analysis of motor / generator; and applications of motor drive, such as Maglev trains, home appliances.

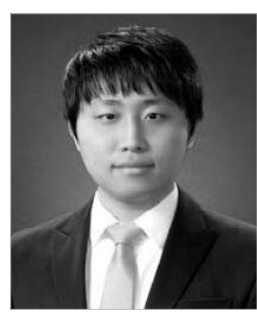

Woong-Chan Chae He received his B.S. and M.S. degrees in Electrical Engineering from Hanyang University, Seoul, Korea in 2011 and 2013, respectively. $\mathrm{He}$ is now working in Hyundai Motor Co. His research interests include motor design, analysis of motor / generator; and applications of motor drive, such as hybrid and electric vehicle.

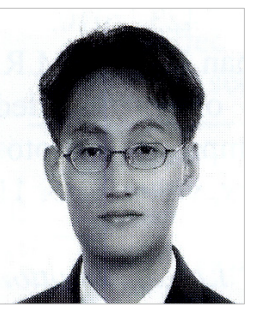

Hyung-Woo Lee He received his M.S. degree from Hanyang University, Seoul, Korea, in 2000, and his Ph.D. from Texas A\&M University, College Station, TX, in 2003, both in Electrical Engineering. He joined Korea National University of Transportation as professor of the department of Railway Vehicle System Engineering in March 2013. His research interests include motor design, analysis of motor / generator; and applications of motor drive, such as Maglev trains, conventional railway propulsion systems, and modern renewable energy systems.

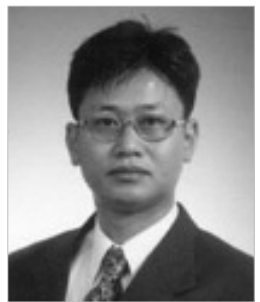

Ju Lee He received his M.S. degree from Hanyang University, Seoul, South Korea, in 1988, and his Ph.D. from Kyusyu University, Japan in 1997, both in Electrical Engineering, $\mathrm{He}$ joined Hanyang University in September, 1997 and is currently a Professor of the Division of Electrical and Biomedical Engineering. His main research interests include electric machinery and its drives, electromagnetic field analysis, new transformation systems such as hybrid electric vehicles (HEV), and high-speed electric trains and standardization. He is a member of the IEEE Industry Applications Society, Magnetics Society, and Power Electronics Society. 